\title{
CORRESPONDENCE
}

\section{Nicotine, tobacco substitutes, and smoking} habits

$S$ Freedman, MRCP, and C M Fletcher,

FRCP; P M Gaylarde.............419

Classification of cigarettes

T D Wyatt, PHD..............420

Orf in Britain

M S Hall, MRCGP...................420

Genetic counselling in Huntington's chorea

A J Caro, MRCGP, and others. . . . . . . .420

Urinary retention in women

S L R Stanton, FRCS; T Moore, FRCS. . . . .420

Amoxycillin, talampicillin, and ampicillin

I W B Grant, FRCPED.

Effect of salicylates on creatinine clearance

P H Plotz, MD, and others.

Superficial carcinoma of the stomach

Ff Fenech, FRCP, and A C Galizia, MD... . . 422

Aplastic anaemia and hair dye

R J Hans, PHD . . . . . . . . . . . . 422

\section{Compulsory seat belts}

J A E Primrose, FRCSED.

Tuberculosis of the colon

I Taylor, FRCs, and P J C Brooman, MB . . .422

Sacrococcygeal teratoma and

"non-immunological" hydrops fetalis

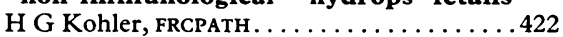

Death from asthma

R B Woodward, мB...........423

"Comprehensive Psychiatric Care"

A A Baker, FRCPSYCH. . . . . . . . . . 423

New look at monoamine oxidase

inhibitors

W W Sargant, FRCP. . . . . . . . . . . . . . 423

Detection of scanty blood parasites

H B Goodall, FRCPATH............423

Management of acute myocardial

infarction

P J Baxter, MRCP, and others . . . . . . . . 423
Requests for references

E W B Varley, Mrcs, fDsRcs . . . . . . . .424

Dextropropoxyphene poisoning

J A Vale, MrCP, and others..........424

Diagnostician of the year

M Honigsberger, FRCPI . . . . . . . . . . 424

Contract dispute

N H N Mills, мғсм..............424

Armchair theorists

N H Harris, fRCS. ................424

United profession

J Fry, fRCGP................425

Membership of Royal Commission

N S Barnett, MB.................425

Points from letters Attitudes and advice after myocardial infarction (Dr R Mulcahy); Effects of pethidine on the newborn (J Mair; J B Spooner); Alcohol in hospital (B H Wilkins);

Community medicine in the eighteenth century

(B N C Littlepage) . . . . . . . . . . . 425

Correspondents are urged to write briefly so that readers may be offered as wide a selection of letters as possible. So many are being received that the omission of some is inevitable. Letters should be signed personally by all their authors.

\section{Nicotine, tobacco substitutes, and smoking habits}

SIR,-We are grateful to Dr R G Rawbone (17 July, p 177) for his comments on our paper (12 June, p 1427). His calculations of observed:expected nicotine intake are interesting and tend to reinforce our conclusions. Men smoking NSM cigarettes got more nicotine from each cigarette, according to Dr Rawbone's calculations, than they would have done if they had smoked them in the same way as they smoked the control cigarettes. But they still got less nicotine, and probably less tar, per cigarette and per day on NSM cigarettes than on control cigarettes or on their own commercially available brands.

Further, the men in group 1 smoked NSM cigarettes for eight months before switching to control cigarettes, so it is probably truer to refer to "undersmoking" of the latter rather than "oversmoking" of NSM cigarettes. This is especially true of the six men who dropped their nicotine intake on going from NSM (1.01 mg nicotine/cigarette) to control (1.39 $\mathrm{mg}$ nicotine/cigarette) and in whom there would have been a big disparity in observed: expected ratios. Dr Rawbone's approach reinforces our conclusions that these men, accustomed to a low nicotine intake, altered their smoking habits so as to keep it low when they switched back to higher nicotine cigarettes.

Our study certainly differs from previous trials in which switching to low nicotine cigarettes led to an increase in cigarette consumption, but only Guillerm's ${ }^{1}$ study was a long-term one, and there, although the increase was significant, it was very small (mean 32 to 34 cigarettes per day) and was due to an increase in only half of his 73 subjects.

We agree that detailed studies of puff volume, duration, frequency, and spacing would be informative. Unfortunately there is no way of making this sort of study under free-smoking conditions. Our own results show that estimated nicotine deliveries may differ from the "machine-smoking" delivery by as much as $0.4 \mathrm{mg}$. Regular measurements of carboxyhaemoglobin levels might be a useful indicator of total smoke inhalation.

S FREEDMAN

C M FLETCHER

Royal Postgraduate

Medical Schoo

${ }^{1}$ Guillerm, R, et al, Bronches, 1974, 24, 211.

SIR,-Dr M A H Russell (12 June, p 1430) points out that the tar : nicotine ratio varies between different brands of cigarette. $\mathrm{He}$ suggests that cigarette smokers tend to regulate their nicotine intake to obtain the customary physiological stimulus and therefore those cigarettes yielding the lowest amounts of tar per $\mathrm{mg}$ of nicotine in the condensate from smoking machines are less hazardous than those brands producing less favourable tar: nicotine ratios.

Cigarettes yield a mixture of compounds on being "smoked," a number of which may be harmful. Carbon monoxide and the tarry distillate are most strongly implicated in smoking induced diseases but oxides of nitrogen and nicotine may be harmful. The tarry condensate obtained from "smoked" cigarettes has long been implicated in the aetiology of lung cancer. The products of the pyrolysis of tobacco vary according to the conditions of combustion. The carcinogenic properties of coal tar are known to increase with increasing temperature of distillation, and it is likely that a similar phenomenon is true of tobacco pyrolysis. Low-temperature pyrolysis is how- ever likely to lead to greater tar yields, which may prove more irritant even though less carcinogenic. Similarly the amount of carbon monoxide depends on the conditions of combustion and may also be influenced by the presence of metal oxides such as ferric oxide, which catalises the conversion $2 \mathrm{CO} \rightleftharpoons \mathrm{C}+\mathrm{CO}_{2}$. This equilibrium is driven in favour of $\mathrm{CO}$ at higher temperatures.

Since the composition of cigarette smoke is influenced by the conditions of combustion and these can be readily varied, I would suggest that research should be undertaken to provide a safer cigarette for smokers. The effect of oxidants to promote even burning, the method of curing of tobacco, the use of bleaching agents, the size of the shreds of tobacco used, the packing density, the diameter of the cigarette, and the use of catalysts and inhibitors to prevent the formation of carbon monoxide and carcinogens could all be studied. The variation in tar: nicotine ratio with nicotine yield (table) suggests that cigarette diameter has a definite effect.

\begin{tabular}{|c|c|c|}
\hline Nicotine group & $\underset{\text { yield }}{\text { Average nicotine }}$ & $\begin{array}{l}\text { Average tar: } \\
\text { nicotine ratio }\end{array}$ \\
\hline $\begin{array}{l}0-0.49 \mathrm{mg} \\
0.50-0.99 \mathrm{mg} \\
1.00-1.24 \mathrm{mg} \\
1.25-1.49 \mathrm{mg} \\
1.50-1.99 \mathrm{mg} \\
\text { greater than } \\
2 \mathrm{mg}\end{array}$ & $\begin{array}{l}0.2025 \pm 0.0989 \\
0.7952 \pm 0.0200 \\
1 \cdot 1450 \pm 0.141 \\
1 \cdot 3575 \pm 0.0100 \\
1.6955 \pm 0.0331 \\
2 \cdot 4855 \pm 0.1600\end{array}$ & $\begin{array}{l}16.48 \pm 1.72 \\
14.28 \pm 0.46 \\
15.12 \pm 0.31 \\
14.17 \pm 0.20 \\
13.50 \pm 0.19 \\
11.96 \pm 0.70\end{array}$ \\
\hline
\end{tabular}

It is of note that studies of lung cancer rates in those countries in which coarsly cut, unbleached tobacco is loosely packed into cigarettes without the addition of oxidants show that the death rates from smoking associated lung cancer are less than half those prevailing in Britain and the United States. This may be pure coincidence, but it is surely worth investigating. Modification of cigarettes by omission of oxidants from their manufacture would be a simple task if their presence were to be proved harmful. However, there is obviously no financial advantage to the 